\title{
Vitamin A deficiency modifies lipid metabolism in rat liver
}

\author{
Liliana B. Oliveros, María A. Domeniconi, Verónica A. Vega, Laura V. Gatica, Ana M. Brigada \\ and María S. Gimenez* \\ Laboratory of Biological Chemistry, Faculty of Chemistry, Biochemistry and Pharmacy, National University of San Luis, \\ Avenida Ejército de los Andes 954, 5700 San Luis, Argentina
}

(Received 11 January 2006 - Revised 24 May 2006 - Accepted 8 June 2006)

\begin{abstract}
Liver fatty acid metabolism of male rats fed on a vitamin A-deficient diet for 3 months from $21 \mathrm{~d}$ of age was evaluated. Vitamin A restriction produced subclinical plasma and negligible liver retinol concentrations, compared with the control group receiving the same diet with 4000 IU vitamin A (8 mg retinol as retinyl palmitate)/kg diet. Vitamin A deficiency induced a hypolipidaemic effect by decreasing serum triacylglycerol, cholesterol and HDL-cholesterol levels. The decrease of liver total phospholipid was associated with low phosphatidylcholine synthesis observed by lower $\left[{ }^{14} \mathrm{C}\right]$ choline incorporation into phosphatidylcholine, compared with control. Also, liver fatty acid synthesis decreased, as was indicated by activity and mRNA expression of acetyl-CoA carboxylase (ACC), and incorporation of $\left[{ }^{14} \mathrm{C}\right]$ acetate into saponified lipids. A decrease of the $\operatorname{PPAR} \alpha$ mRNA expression was observed. Liver mitochondria of vitamin A-deficient rats showed a lower total phospholipid concentration coinciding with a decrease of the cardiolipin proportion, without changes in the other phospholipid fractions determined. The mitochondria fatty acid oxidation increased by $30 \%$ of the control value and it was attributed to a high activity and mRNA expression of carnitine palmitoyltransferase-I (CPT-I). An increase in serum $\beta$-hydroxybutyrate levels was observed in vitamin A-deficient rats. Vitamin A deficiency alters the mitochondria lipid composition and also enhances fatty acid oxidation by modifiying the production of malonyl-CoA, the endogenous inhibitor of CPT-I, due to decreased activity of liver ACC. The incorporation of vitamin A into the diet of vitamin A-deficient rats reverted all the changes observed.
\end{abstract}

Vitamin A deficiency: Carnitine palmitoyltransferase-I: Acetyl-CoA carboxylase: PPAR $\alpha$ : Liver

Vitamin A deficiency is an important public health problem in many developing nations. Particularly, marginal vitamin A deficiency is associated with increased morbidity and mortality in young children (Humphrey et al. 1992; Fawzi et al. 1993). Vitamin A is a generic term which describes a number of molecules exhibiting the biological activity of retinol, the precursor of naturally occurring retinoids. It is an essential nutrient required for vision, growth, embryological development, cell differentiation, reproduction, maintenance of mucous secretion and apoptosis in man and rats. The molecular mechanism of retinoic acid action mainly involves the binding and activation of specific nuclear receptors, retinoic acid receptor and retinoid $\mathrm{X}$ receptor, that modulate gene expression (Chambon, 2005). The liver is the body's main storage site for vitamin A and also regulates the secretion of retinol into the circulation in response to the demands of vitamin A-requiring target tissues (Blomhoff et al. 1990).

A relationship between vitamin A nutritional status and blood lipids has been indicated. It is known that vitamin A and its derivatives cause hypertriglyceridaemia with high levels of intake (Dicken, 1881). On the other hand, it has been revealed that vitamin A deficiency in maturing male rats results in hypotriglyceridaemia and increased microviscosity of liver lipids (Kon'IIa et al. 1990) and also in a decrease of antioxidant defences leading to hepatic lipoperoxidation (Oliveros et al. 2000; Korichneva et al. 2003).

Acetyl-CoA carboxylase (ACC) catalyses the first step committed to fatty acid synthesis and is generally accepted to be a potentially rate-limiting enzyme in that pathway. Mammals have two major isoforms of ACC ( $\alpha$ and $\beta$ ). ACC $\alpha$ is the major isoform in lipogenic tissues such as adipose and liver tissue, and ACC $\beta$ has a predominant location in heart and skeletal muscles (López-Casillas \& Kim, 1991). The carboxylation of acetyl-CoA by ACC produces malonyl-CoA, which participates in fatty acid biosynthesis and also acts as a physiological regulator of fatty acid oxidation in the liver through inhibition of carnitine palmitoyltransferase-I (CPT-I; McGarry \& Brown, 1997). CPT-I is an integral protein of the outer mitochondrial membrane that catalyses the initial reaction in the mitochondrial import of long-chain fatty acid-CoA where they are oxidized. This is a tightly regulated step in the cellular fatty acid utilization pathway. The enzyme exists as two isoforms encoded by separated genes, the liver-type (L-CPT-I or CPT-IA), a hepatic-enriched, ubiquitously expressed protein (McGarry, 1995), and the muscle-type (M-CPT-I or CPT-IB) that is highly expressed in heart, skeletal muscle, brown and white adipocytes and testes (Esser et al. 1996). Retinoids have been proposed to regulate

Abbreviations: ACC, acetyl-CoA carboxylase; CPT-I, carnitine palmitoyltransferase-I.

* Corresponding author: Dr María S. Gimenez, fax +54 2652 430224/431301, email mgimenez@unsl.edu.ar 
mitochondrial processes. The existence of a retinoic acid binding protein associated with mitochondria that binds and keeps retinoic acid in the mitochondria has been described (Ruff \& Ong, 2000).

The expression of several genes involved in intra- and extracellular lipid metabolism is mediated by ligand-activated receptors, collectively referred to as PPAR. PPAR activate or repress gene expression in response to cognate ligands by binding in conjunction with the obligate heterodimerization partner, retinoid $\mathrm{X}$ receptor, to specific cis-acting regulatory elements called peroxisome proliferator-response elements present in the promoter regions of target genes (Berger \& Moller, 2002). Three different isoforms ( $\alpha, \gamma$ and $\delta$ ) have been identified and found to exhibit tissue-specific distributions; although all three exert broad regulatory effects primarily on lipid homeostasis, $\operatorname{PPAR} \alpha$ predominantly regulates pathways of fatty acid oxidation (Issemann et al. 1993). Cross-talk between retinoid X receptor and PPAR $\alpha$ in the liver, activated by rexinoids (selective retinoid $\mathrm{X}$ receptor-activators), has been reported (Ouamrane et al. 2003).

In view of the previous observations, it was of interest to study the influence of retinol deficiency on liver fatty acid metabolism since this organ plays a major role in long-chain fatty acid and vitamin A metabolism. We examined the synthesis and oxidation of fatty acids and the mRNA expression of enzymes of regulatory importance involved in those processes. Also, the mRNA PPAR $\alpha$ was analysed in the liver of vitamin A-deficient rats. Results were compared to the corresponding data from rats fed on an isoenergetic sufficient vitamin A diet. Finally, the effect of vitamin A restitution to vitamin A-deficient rats on lipid metabolism was analysed.

\section{Materials and methods}

\section{Chemicals and radioisotopes}

$\left[{ }^{14} \mathrm{C}\right] \mathrm{NaCO}_{3} \mathrm{H}^{-}(266 \cdot 4 \mathrm{MBq} / \mathrm{mmol})$, acetic acid, $\left[1-{ }^{14} \mathrm{C}\right]$ sodium salt $(73.99 \mathrm{MBq} / \mathrm{mmol})$ and $\left[\mathrm{N}-\mathrm{Me}-{ }^{14} \mathrm{C}\right] \mathrm{L}$-carnitine were purchased from Dupont, New England Company (Boston, MA, USA). Retynil-palmitate, all-trans retinol and lipids standards were acquired from Sigma Chemical Co. (St Louis, MO, USA). All other chemicals were reagent grade and were obtained from Merck Laboratory (Buenos Aires, Argentina).

\section{Diet and experimental design}

Male Wistar rats were obtained from Romanelli S.R.L. (Buenos Aires, Argentina). Rats at $21 \mathrm{~d}$ old were housed individually in stainless steel cages and randomly divided into two groups (eight per group) given either the experimental diet, devoid of vitamin A (vitamin A-deficient diet), or the same diet (control diet) supplemented with $4000 \mathrm{IU}$ vitamin A (8 $\mathrm{mg}$ retinol as retinyl palmitate) $/ \mathrm{kg}$ diet. Also, a group of eight deficient animals were fed with the control diet $15 \mathrm{~d}$ before being killed (vitamin A-refed group) for determination of mRNA expressions. Rats were housed in individual cages and kept in a $21-23^{\circ} \mathrm{C}$ controlled environment with a $12 \mathrm{~h}$ light-dark cycle. They were given free access to food and water throughout the entire 3 months of the experimental period. The experiment was conducted according to our committee recommendations for animal care. Diets were prepared according to AIN-93 for laboratory rodents (Reeves et al. 1993). The diets have the following composition $(\mathrm{g} / \mathrm{kg})$ : 397.5 maize starch, 100 sucrose, 132 dextrinized maize starch, 200 vitamin-free casein, 70 soyabean oil, 50 cellulose fibre, 35 AIN-93 mineral mix, 10 AIN-93 vitamin mix (devoid of vitamin A for the vitamin A-deficient diet), 3 L-cystine, 2.5 choline bitartrate and 0.014 tert-butylhydroquinone. Body weight and food intake were registered daily.

\section{Plasma and liver retinol concentration analyses}

Rats were killed by cervical dislocation at 09:00 hours. Blood samples were collected in EDTA-coated tubes. The liver was separated, immediately washed several times in ice-cold isotonic saline, blotted on paper to remove excess blood and then weighed. To minimize photoisomerization of vitamin A the plasma and tissues samples were taken under reduced yellow light and frozen in the dark at $-70^{\circ} \mathrm{C}$ until determination of retinol concentrations. Analyses were carried out within 1-3 weeks of obtaining the samples. Plasma and tissue retinol concentration was determined by HPLC (Bieri et al. 1979). Retinoids were extracted from plasma $(0.5 \mathrm{ml})$ into hexane containing $5 \mu \mathrm{g}$ butylated hydroxytoluene/ml as antioxidant for analysis. To determine tissue retinol mass, triplicate aliquots $(0.2 \mathrm{~g})$ of tissue were homogenized in deionized water, lyophilized and saponified in $1 \mathrm{ml}$ ethanolic solution containing $0.9 \mathrm{~mol} / \mathrm{l}$ potassium hydroxide for $1 \mathrm{~h}$ at $60^{\circ} \mathrm{C}$ under nitrogen atmosphere. Retinyl acetate was used as internal standard. Retinol and internal standard were extracted into hexane for analysis. Chromatography was performed on a Nucleosil 125 C-18 HPLC column with methanol-water (95:5, v/v) as the mobile phase. Retinol was detected by UV absorbance at $325 \mathrm{~nm}$ (Model 440; Waters Associates, Milford, MA, USA) and peak areas were calculated by integration (Spectra Physics Analytical, San Jose, CA, USA).

\section{Serum lipid, glucose and $\beta$-hydroxybutyrate determinations}

Glucose, lipid and $\beta$-hydroxybutyrate concentrations were detemined using fresh serum from rats that had been starved for $12 \mathrm{~h}$. Serum glucose, cholesterol and HDL-cholesterol were determined by enzymatic methods using kits from Boehringer Mannheim Diagnostics (Indianapolis, IN, USA). Serum $\beta$-hydroxybutyrate was analysed using an enzyme colorimetric assay (Sigma Chemical Co.).

\section{Liver acetyl-CoA carboxylase activity}

The activity of ACC (EC 6.4.1.2) was measured in the cytosolic fraction of liver using $\left[{ }^{14} \mathrm{C}\right] \mathrm{NaCO}_{3} \mathrm{H}^{-}(266.4 \mathrm{MBq} / \mathrm{mmol})$ according to the method of Allred \& Roehrig (1978). The liver was homogenized in an Ultra Turrax T25 machine with 1.5 volumes of cold $0.3 \mathrm{M}$-manitol and centrifuged at $100000 \mathrm{~g}$ for $1 \mathrm{~h}$ with a Beckman model L2 65B ultracentrifuge. Results were expressed in pmol $\left[{ }^{14} \mathrm{C}\right] \mathrm{NaCO}_{3} \mathrm{H}^{-}$fixed/ mg protein per min. Enzymatic assays were conducted in duplicate. Protein concentration was determined using the method of Lowry et al. (1951). 


\section{Incorporation of $\left[{ }^{14}\right.$ C]acetate into liver lipids}

Liver slices $(100 \mathrm{mg})$ were preincubated in $0.5 \mathrm{ml}$ Krebs Ringer-glucose solution, $\mathrm{pH} 7 \cdot 2$, for $10 \mathrm{~min}$ at $37^{\circ} \mathrm{C}$ in a $95 \%$ air $-5 \% \quad \mathrm{CO}_{2}$ atmosphere. Then the medium was replaced by $1.0 \mathrm{ml}$ fresh Krebs Ringer solution with $\left[{ }^{14} \mathrm{C}\right]$ acetate $(0.04 \mathrm{MBq})$ added and the different samples were incubated for $60 \mathrm{~min}$. The reaction was stopped by addition of

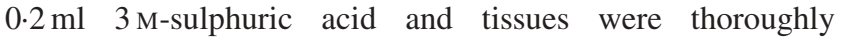
washed in ice-cold Krebs Ringer solution until no more radioactivity was detected in the wash solution before storing samples at $-70^{\circ} \mathrm{C}$ until use. Lipids were saponified by treatment with $10 \%(\mathrm{w} / \mathrm{v}) \mathrm{KOH}$ in ethanol-water $(100: 15$, v/v) for $3 \mathrm{~h}$ at $80^{\circ} \mathrm{C}$. NEFA were recovered from the lower phase after acidification with $0.3 \mathrm{ml} 1.2 \mathrm{M}-\mathrm{HCl}$ and extracted three times with petroleum ether $\left(2.5 \mathrm{ml}\right.$, boiling point $\left.30-40^{\circ} \mathrm{C}\right)$. This fraction was dried down in a stream of nitrogen before counting its radioactivity. Aliquots of the non-saponified fraction (upper phase) were used for separation of the cholesterol fraction by TLC before counting its radioactivity in a Wallac 1409 DSA liquid scintillation counter. The results are expressed as $\mu \mathrm{mol}\left[{ }^{14} \mathrm{C}\right]$ acetate incorporated/h per mg protein.

\section{Incorporation of $\left[1-{ }^{14} \mathrm{C}\right]$ choline into phosphatidylcholine}

Slices of liver were preincubated in $0.5 \mathrm{ml}$ Krebs Ringer-glucose solution, $\mathrm{pH} 7 \cdot 2$, for $10 \mathrm{~min}$ at $37^{\circ} \mathrm{C}$ in a $95 \%$ air $-5 \%$ $\mathrm{CO}_{2}$ atmosphere. After that, the medium was replaced by $0.5 \mathrm{ml}$ fresh Krebs Ringer solution added with $\left[1-{ }^{14} \mathrm{C}\right]$ choline $(0.04 \mathrm{MBq})$ added and the different samples were incubated for $60 \mathrm{~min}$. The reaction was stopped by addition of $0.2 \mathrm{ml}$ $3 \mathrm{M}$-sulphuric acid and tissues were thoroughly washed in ice-cold Krebs Ringer solution until no more radioactivity was detected in the wash solution. Phospholipid classes were separated by TLC (described earlier) and bands were scraped off and their radioactivity quantified. The results are expressed as pmol $\left[1-{ }^{14} \mathrm{C}\right]$ choline incorporated/h per $\mathrm{mg}$ protein.

\section{Preparation of mitochondria}

Liver mitochondria were prepared according to McGarry et al. (1983) by isolating them from the low-speed nuclear pellet of the original homogenate that yields mitochondria with only minimal contamination from other subcellular organelles. Briefly, livers were removed, immediately thereafter washed several times in ice-cold isotonic saline and chopped with scissors in ice-cold $0.25 \mathrm{~mol} / \mathrm{l}$ sucrose. The medium was decanted and the tissue was resuspended in 10 volumes of fresh medium and then homogenized in a Teflon pestle in a $10 \mathrm{ml}$ PotterElvehjem homogenizer mantained in ice throughout. The homogenate was centrifuged at $1000 \mathrm{~g}$ for $15 \mathrm{~min}$. The supernatant was discarded and replaced with an equivalent volume of medium. The pellet was rehomogenized and centrifuged at $600 \mathrm{~g}$ for $10 \mathrm{~min}$. The supernatant was used as the source for mitochondria, and it was pelleted by centrifugation at $15000 \mathrm{~g}$ for $15 \mathrm{~min}$. The mitochondrial pellet was washed twice with $0.25 \mathrm{~mol} / 1$ sucrose and $0.15 \mathrm{M}-\mathrm{KCl}$ and finally resuspended in the latter and kept on ice until used (within $30 \mathrm{~min}$ ). Protein was measured by the method of Lowry et al. (1951). Preparations of mitochondria were practically devoid of peroxisomes, as judged from measurements of catalase activity $(<4 \%)$ of the total homogenate catalase activity when assayed by the method of Chance et al. (1979).

\section{Lipid determinations in hepatic tissue and mitochondria}

The lipids from hepatic tissue and mitochondria were extracted with chloroform-methanol (2:1) according to the method of Folch et al. (1957). An aliquot of the lipid extracts was taken to determine total cholesterol, and another one to separate the different lipid fractions by TLC using plates coated with silica gel G (Merck, Darmstadt, Germany), with an $n$-hexane-diethyl ether-acetic acid (80:20:1, by vol.) solvent system. Lipids were detected by exposing the plates to iodine vapours. After eluting the scraped bands, aliquots were used for mass determination according to the methods of Rauser et al. (1970) for phospholipids, of Sardesai \& Manning (1968) for triacylglycerols and of Zak et al. (1954) after saponification (Abell et al. 1952) for free and esterified cholesterol. On average, $93 \%$ of cholesterol mass was recovered by TLC.

Phospholipids were separated into component species by TLC using silica gel $G$ plates and chloroform-methanolwater (65:25:4, by vol.) as the solvent system. The individual phospholipids were identified, recovered and quantified for phosphorus content as described earlier. The results were expressed as percentage of total phospholipid phosphorus content. The position of neutral lipids and individual phospholipids was determined using the respective standard lipids.

\section{Carnitine palmitoyltransferase-I activity}

The activity of CPT-I was assayed using a method similar to that described by Grantham \& Zammit (1986) with some modifications. The CPT-I activity was measured in mitochondria ( $400 \mu \mathrm{g}$ protein) at $37^{\circ} \mathrm{C}$ in the direction: palmitoyl-CoA $+\left[{ }^{14} \mathrm{C}\right]$ carnitine $\rightarrow\left[{ }^{14} \mathrm{C}\right]$ palmitoylcarnitine $+\mathrm{CoA}$. Assays were performed in a medium containing $150 \mathrm{mmol} / \mathrm{l}$ $\mathrm{KCl}, 5 \mathrm{~mm}$-Tris- $\mathrm{HCl} \quad(\mathrm{pH}$ 7.4), $1 \mathrm{mmol} / \mathrm{l}$ dithiothreitol, $80 \mu \mathrm{mol} / \mathrm{l}$ palmitoyl-CoA, $1 \mathrm{mmol} / \mathrm{l}$ EGTA, $1.3 \mathrm{~g} / \mathrm{l}$ defatted bovine serum albumin, $1 \mathrm{mg} / \mathrm{l}$ rotenone and $1 \mathrm{mg} / \mathrm{l}$ antimicyn A. The mitochondria were preincubated in this medium for $5 \mathrm{~min}$ at $37^{\circ} \mathrm{C}$ before the initiation of the reaction. The reaction ( $500 \mu \mathrm{l}$ final volume) was started with $0.2 \mathrm{mmol} / \mathrm{l}$ carnitine and $\mathrm{L}-\left[\mathrm{N}-\mathrm{Me}-{ }^{14} \mathrm{C}\right]$ carnitine $(0 \cdot 04 \mathrm{MBq})$. After $4 \mathrm{~min}$ the reaction was stopped with $1 \mathrm{ml}$ ice-cold $1.2 \mathrm{~mol} / \mathrm{l} \mathrm{HCl}$, and watersaturated 1-butanol was added to extract the product palmitoyl- $\left[{ }^{14} \mathrm{C}\right]$ carnitine. Aliquots were assayed for radioactivity in a Wallac 1409 DSA liquid scintillation counter. Assays were run in duplicate and performed under conditions where product formation was linear with respect to both time of incubation and amount of protein.

\section{RNA isolation and RT-PCR analysis of acetyl-CoA} carboxylase, carnitine palmitoyltransferase-I and PPAR $\alpha$

Total RNA was isolated from $200 \mathrm{mg}$ liver using TRIzol (Life Technologies, New York, USA). All RNA isolations were performed as directed by the manufacturers. Gel electrophoresis and ethidium bromide staining confirmed the purity and integrity of the samples. Quantification of RNA was based on spectrophotometric analysis at $260 / 280 \mathrm{~nm}$. Total RNA $(10 \mu \mathrm{g})$ 
was reverse-transcribed with 200 U MMLV RT (Promega Inc., Madison, WI, USA) using random hexamers as primers in a $20 \mu \mathrm{l}$ reaction mixture, following the manufacturer's instructions. RT-generated fragments coded for $\beta$-actin (Choi \& Choi, 2000), ACC (Zhou et al. 1999), CPT-I (Zhou et al. 1999) and PPAR $\alpha$ (Hoekstra et al. 2003). PCR was performed in $35 \mu \mathrm{l}$ reaction solution containing $0.2 \mathrm{mM}-\mathrm{dNTP}, 1.5 \mathrm{mM}-$ $\mathrm{MgCl}_{2}, 1.25 \mathrm{U}$ Taq polymerase, $50 \mathrm{pmol}$ of each rat specific oligonucleotide primer and RT product (1/10 of RT reaction). The sequences of the different primers are shown on Table 1. The predicted sizes of the PCR-amplified products were $243 \mathrm{bp}$ for $\beta$-actin, $535 \mathrm{bp}$ for ACC, $629 \mathrm{bp}$ for CPT-I and $106 \mathrm{bp}$ for PPAR $\alpha$. The samples were heated to $94^{\circ} \mathrm{C}$ for $2 \mathrm{~min}$, followed by thirty-five temperature cycles. Each cycle consisted of three periods: (1) denaturation, $94^{\circ} \mathrm{C}$ for $1 \mathrm{~min}$; (2) annealing, $58^{\circ} \mathrm{C}$ for ACC, CPT-I and $\beta$-actin, and $60^{\circ} \mathrm{C}$ for PPAR $\alpha$ for $1 \mathrm{~min}$; (3) extension, $72^{\circ} \mathrm{C}$ for $1 \mathrm{~min}$. After thirty-five reaction cycles, the extension reaction was continued for another $5 \mathrm{~min}$ (Thermal Cycler 2400, Perkin-Elmer).

The PCR products were electrophoresed on $2 \%(\mathrm{w} / \mathrm{v})$ agarose gel with $0.01 \%(\mathrm{w} / \mathrm{v})$ ethidium bromide. The image was visualized and photographed under UV transillumination. The intensity of each band was measured using National Institutes of Health Image software and reported as the values of band intensity units.

\section{Statistical analyses}

Data are presented as means and their standard errors. Significant differences among means were considered at a level of $P<0.05$ and identified by one-way ANOVA.

\section{Results}

Body and liver weight, plasma and liver retinol, and serum lipids

The initial body weight of the rats in the three dietary groups was similar. At the time of killing, there was a significant effect of vitamin A deficiency on body weight gain, while that of the vitamin A-refed group was near to control and significantly higher than that of vitamin A-deficient rats $(P<0.05)$. The liver weight did not change among groups.

Since plasma retinol is not directly representative of liver vitamin A stores, the vitamin A deficiency was confirmed by analysis of liver concentrations of retinol. The plasma retinol concentrations of rats fed on the vitamin A-deficient diet were significantly lower $(P<0.001)$ than those of control. Total liver retinol stores of vitamin A-deficient rats were depleted, being $<7 \%$ of the accumulated total liver retinol stores of control rats. Vitamin A refeeding considerably increased the plasma and liver vitamin A concentrations in relation to vitamin A-deficient rats.

Vitamin A deficiency resulted in a significant decrease in serum triacylglycerol, cholesterol and HDL-cholesterol concentrations, but did not modify serum VLDL + LDL-cholesterol. The serum $\beta$-hydroxybutyrate levels increased $(+30 \%)$ compared with control. In spite of a tendency toward lower serum glucose levels in the vitamin A-deficient rats compared with control rats, no statistical difference was observed. In the vitamin A-refed group serum $\beta$-hydroxybutyrate and all lipid levels reached the control values (Table 2).

Changes in lipid profile of liver with vitamin A-deficient diet

As shown in Table 3, vitamin A deficiency affected the content of liver total phospholipids. Its concentration decreased, while cholesterol and triacylglycerol did not change in the vitamin A-deficient group in relation to those of the control group. Consequently, the ratio of total cholesterol/phospholipids increased $(P<0.05)$ in the liver of vitamin A-deficient rats. Vitamin A refeeding normalized the phospholipid content.

Effect of vitamin A deficiency on the synthesis of phosphatidylcholine, sphingomyelin, fatty acids and cholesterol in liver slices

The $\left[{ }^{14} \mathrm{C}\right]$ choline incorporated into phosphatidylcholine by liver was decreased by $\sim 43 \%$ in the vitamin A-deficient rats, without change in sphingomyelin, when compared with control. The $\left[{ }^{14} \mathrm{C}\right]$ acetate incorporated into the saponifiable lipid fraction, indicating de novo synthesis of fatty acids, was decreased in liver from vitamin A-deficient rats $(P<0 \cdot 001)$.

No change in non-saponifiable (cholesterol) lipid fractions was observed.

In the vitamin A-refed animals the decrease of $\left[{ }^{14} \mathrm{C}\right]$ choline incorporation into phosphatidylcholine and that of $\left[{ }^{14} \mathrm{C}\right]$ acetate into fatty acids were partially reversed (Table 4).

\section{Liver acetyl-CoA carboxylase activity: effect of vitamin A deficiency}

As shown in (Fig. 1), the ACC activity was significantly lower (by $36 \%$ ) in the liver of vitamin A-deficient rats than those of controls. Vitamin A refeeding in deficient animals did not completly restored the enzyme activity to control values. The cytosolic protein concentration was not modified among the three groups in the supernatant used to measure the enzyme activity (data not shown). Thus, the change observed in the enzyme activity was specifically due to change in

Table 1. Sequences of the primers used to amplify the different genes by RT-PCR and sizes of the fragments generated

\begin{tabular}{llllr}
\hline Gene & Gen Bank accession & \multicolumn{1}{c}{ Forward primer } & Reverse primer & Amplicon size (bp) \\
\hline$\beta$-Actin & NM 031144 & CGTGGGCCGCCCTAGGCACCA & TTGGCCTTAGGGTTCAGAGGGG & 243 \\
CPT-I & L07736 & TATGTGAGGATCTGCTTCC & CTCGGAGAGCTAAGCTTGTC & 629 \\
ACC & M76767 & ACTCCAGGACAGCACAGATC & TCTGCCAGTCCAATTCTAGC & 535 \\
PPAR $\alpha$ & NM013196 & TGAACAAAGACGGGATG & TCAAACTTGGGTTCCATGAT & 106 \\
\hline
\end{tabular}

ACC, acetyl-CoA carboxylase; CPT-I, carnitine palmitoyltransferase-I. 
Table 2. Body and liver weight, plasma and tissue retinol levels, and serum lipids and $\beta$-hydroxybutyrate in vitamin A-deficient rats (eight rats per dietary group)‡

(Mean values with their standard errors)

\begin{tabular}{|c|c|c|c|c|c|c|}
\hline & \multicolumn{2}{|c|}{ Control } & \multicolumn{2}{|c|}{ Vitamin A-deficient } & \multicolumn{2}{|c|}{ Vitamin A-refed } \\
\hline & Mean & SEM & Mean & SEM & Mean & SEM \\
\hline Initial body wt (g) & $49 \cdot 50$ & $2 \cdot 2$ & $51 \cdot 03$ & $2 \cdot 4$ & $52 \cdot 01$ & $2 \cdot 8$ \\
\hline Body wt gain (g) & 313.5 & $8 \cdot 1$ & $275 \cdot 1^{*} \dagger$ & $6 \cdot 4$ & $309 \cdot 7$ & 8.5 \\
\hline Total liver wt (g) & $12 \cdot 9$ & 0.73 & 11.05 & 0.67 & 11.9 & 0.84 \\
\hline Liver retinol $(\mu \mathrm{mol} / \mathrm{g} \mathrm{wt})$ & 1.65 & 0.06 & $0 \cdot 11^{* *}+\dagger \dagger$ & 0.01 & 1.48 & 0.05 \\
\hline Plasma retinol $(\mu \mathrm{mol} / \mathrm{l})$ & 1.42 & 0.05 & $0.45^{\star * *}+\dagger \dagger$ & 0.02 & 1.33 & 0.06 \\
\hline Serum glucose $(\mathrm{mg} / \mathrm{dl})$ & 119 & $6 \cdot 1$ & 107 & $2 \cdot 8$ & 113 & $3 \cdot 7$ \\
\hline Serum $\beta$-hydroxybutyrate (mg/dl) & 8.63 & 0.24 & $12 \cdot 50^{\star} \dagger$ & 0.57 & 8.01 & 0.63 \\
\hline Triacylglycerol (mg/dl) & $80 \cdot 45$ & $1 \cdot 11$ & $59 \cdot 09^{\star \star \star}+\dagger \dagger$ & $1 \cdot 16$ & $75 \cdot 97$ & 1.34 \\
\hline Total cholesterol (mg/dl) & $57 \cdot 12$ & $2 \cdot 16$ & $40 \cdot 33^{\star \star}+\dagger$ & $1 \cdot 27$ & $55 \cdot 65$ & $2 \cdot 31$ \\
\hline HDL-cholesterol (mg/dl) & $42 \cdot 47$ & 1.90 & $29.53^{*} \dagger$ & 1.45 & 41.06 & 1.85 \\
\hline LDL + VLDL-cholesterol (mg/dl) & 14.41 & 1.71 & 11.01 & 1.36 & 13.78 & 1.90 \\
\hline
\end{tabular}

Mean values were significantly different from those of the control group (one-way ANOVA): ${ }^{\star} P<0.05 ;{ }^{\star *} P<0.01$; ${ }^{* \star *} P<0.001$.

Mean values were significantly different from those of the vitamin A-refed group (one-way ANOVA): $+P<0.05$ $\dagger \uparrow P<0.01 ; \dagger \uparrow \uparrow P<0.001$.

‡For details of procedures, see pp. 264-265.

the activity itself but it was not influenced by the total soluble protein concentration.

\section{Mitochondrial carnitine palmitoyltransferase-I activity: effect of vitamin A deficiency}

The CPT-I activity in the liver mitochondria of rats fed on the vitamin A-deficient diet was increased by $40 \%$ of the control value. This increase was reverted by vitamin A refeeding, reaching values similar to control (Fig. 2).

\section{Liver mitochondria lipid content}

The content of the different mitochondrial lipids of liver is showed in Table 5. The concentration of triacylglycerols increased and total phospholipid contents decreased in the vitamin A-deficient group in relation to that of the control group. The vitamin A refeeding partially restored the phospholipid content. In spite of a tendency toward recovering the triacylglycerol mass and cholesterol/phospholipid ratio after vitamin A refeeding, no statistical differences were observed compared with vitamin A-deficient rats. No changes in cholesterol contents among the three groups were observed.

On a percentage basis the phospholipid composition was modified in the mitochondria of vitamin A-deficient rats, showing a significant decrease in cardiolipin content $(P<0 \cdot 01)$ compared with controls. No change in phosphatidylcholine, phosphatidylethanolamine, sphingomyelin and phosphatidylinositol + phosphatidylserine content was observed (Table 6).

Vitamin A deficiency on the levels of mRNA expression of carnitine palmitoyltransferase-I, acetyl-CoA carboxylase and PPAR $\alpha$

As shown in Fig. 3, the expression of CPT-I mRNA, the main regulator of fatty acid $\beta$-oxidation, was increased in vitamin A-deficient rats $(P<0 \cdot 01)$ as compared to controls and totally restored by the vitamin A refeeding. The expression of ACC mRNA was significantly lower in liver from vitamin A-deficient rats than those from control and vitamin A-refed

Table 3. Effect of vitamin A deficiency on liver lipid composition ( $\mu \mathrm{mol} / \mathrm{g}$ liver; eight rats per dietary group)‡

(Mean values with their standard errors)

\begin{tabular}{|c|c|c|c|c|c|c|}
\hline & \multicolumn{2}{|c|}{ Control } & \multicolumn{2}{|c|}{ Vitamin A-deficient } & \multicolumn{2}{|c|}{ Vitamin A-refed } \\
\hline & Mean & SEM & Mean & SEM & Mean & SEM \\
\hline Triacylglycerol & $10 \cdot 12$ & 2.51 & $11 \cdot 01$ & 0.86 & $9 \cdot 76$ & $1 \cdot 35$ \\
\hline Total cholesterol & $6 \cdot 80$ & 0.48 & $6 \cdot 31$ & 0.64 & 7.05 & $0 \cdot 21$ \\
\hline Free cholesterol & $6 \cdot 01$ & 0.75 & $5 \cdot 60$ & 0.93 & 6.43 & 0.46 \\
\hline Esterified cholesterol & 0.79 & 0.05 & 0.69 & 0.08 & 0.62 & 0.07 \\
\hline Phospholipids & $35 \cdot 60$ & 0.97 & $27 \cdot 01^{*} \dagger$ & 1.03 & $37 \cdot 03$ & 0.82 \\
\hline Total cholesterol/phospholipids & $0 \cdot 19$ & 0.06 & $0 \cdot 24^{* *}+\dagger$ & 0.04 & $0 \cdot 19$ & 0.05 \\
\hline
\end{tabular}

Mean values were significantly different from those of the control group (one-way ANOVA): ${ }^{\star} P<0.05 ;{ }^{* \star} P<0.01$.

Mean values were significantly different from those of the vitamin A-refed group (one-way ANOVA): $\dagger P<0.05$; $\dagger+P<0.01$.

‡For details of procedures, see pp. 264-265. 
Table 4. Incorporation of $\left[1-{ }^{14} \mathrm{C}\right]$ acetate into saponified and non-saponified lipid fractions, and [methyl $-{ }^{14} \mathrm{C}$ ]choline into phosphatidylcholine and sphingomyelin (two experiments with four rats per dietary group) $\ddagger$

(Mean values with their standard errors)

\begin{tabular}{|c|c|c|c|c|c|c|}
\hline & \multicolumn{2}{|c|}{ Control } & \multicolumn{2}{|c|}{ Vitamin A-deficient } & \multicolumn{2}{|c|}{$\begin{array}{l}\text { Vitamin A- } \\
\text { refed }\end{array}$} \\
\hline & Mean & SEM & Mean & SEM & Mean & SEM \\
\hline \multicolumn{7}{|c|}{ Incorporation of $\left[1-{ }^{14} \mathrm{C}\right]$ acetate $(\mu \mathrm{mol} / \mathrm{h}$ per $\mathrm{mg}$ protein) } \\
\hline Fatty acids (saponified lipids) & 6.52 & 0.72 & $3 \cdot 73^{\star * \star} \dagger$ & 0.28 & $5 \cdot 25$ & 0.76 \\
\hline Cholesterol (non-saponified lipid) & 0.70 & 0.08 & 0.65 & 0.09 & 0.81 & 0.10 \\
\hline \multicolumn{7}{|c|}{ Incorporation of [methyl- $\left.{ }^{-14} \mathrm{C}\right]$ choline (pmol/h per mg protein) } \\
\hline Phosphatidylcholine & $33 \cdot 12$ & $2 \cdot 41$ & $18 \cdot 07^{\star \star \star} \dagger$ & 1.76 & $26 \cdot 02$ & $2 \cdot 05$ \\
\hline Sphingomyelin & $9 \cdot 22$ & $2 \cdot 17$ & $7 \cdot 89$ & $1 \cdot 18$ & 7.96 & 1.55 \\
\hline
\end{tabular}

Mean values were significantly different from those of the control group (one-way ANOVA): ${ }^{\star \star \star} P<0 \cdot 001$.

Mean values were significantly different from those of the vitamin A-refed group (one-way ANOVA): $† P<0.05$.

‡For details of procedures, see pp. 264-265.

groups. The restitution of vitamin A to the diet of vitamin Adeficient rats did not completely restore the ACC mRNA expression to control values.

A significant decrease of $\operatorname{PPAR} \alpha$ mRNA expression $(P<0 \cdot 001)$ was observed in vitamin A-deficient rats in relation to control. The vitamin A refeeding reverted that change, reaching values similar to control indicating that PPAR $\alpha$ could be involved in the effects of vitamin A deficiency.

\section{Discussion}

The present in vivo study was undertaken to investigate the effect of vitamin A deprivation on liver fatty acid metabolism. The quantity of retinol stored in the neonatal liver during the nursing period is greatly influenced by maternal diet during lactation. We did not restrict the vitamin A intake of the dams of the experimental rats, and for this reason we prolonged the vitamin A dietary deficiency for 3 months. Plasma retinol levels alone do not

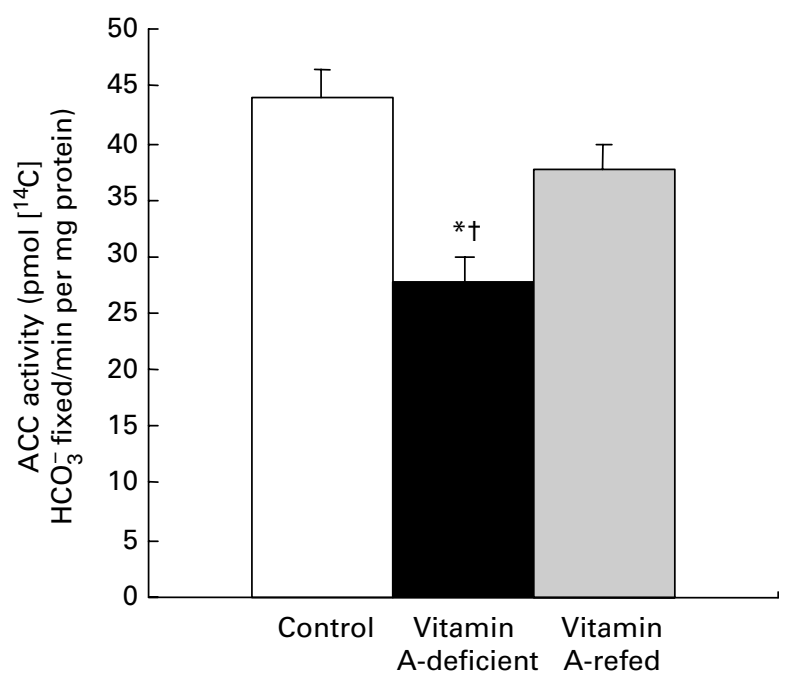

Fig. 1. Acetyl-CoA carboxylase (ACC) activity in the liver of control, vitamin Adeficient and vitamin A-refed rats. For details of procedures, see pp. 264-265. Values are means with their standard errors depicted by vertical bars (eight rats per dietary group). Mean value was significantly different from that of the control group: ${ }^{*} P<0.001$. Mean value was significantly different from that of the vitamin A-refed group: $\dagger P<0.01$. reliably predict liver stores unless the plasma level reaches $<0.35 \mu \mathrm{mol} / \mathrm{l}$ (Olson, 1982). In the present study, the 3 months of vitamin A deprivation after weaning produced subclinical plasma retinol concentration and negligible total retinol stores in the liver; the data confirmed vitamin A deficiency. Lower body weights of vitamin A-depleted rats has also been shown by other authors (Wright et al. 2002). We have previously demonstrated that deprivation of vitamin A for 3 months does not affect daily food intake in relation to control rats (Oliveros et al. 2000).

It is well established that liver phospholipid content decreases in rats with vitamin A deficiency (Khanna \& Reddy, 1983) and, by contrast, it increases in guinea pigs with the administration of $30 \mathrm{mg}$ retinol for $7 \mathrm{~d}$ (Alarcon Corredor et al. 1996). In the present study, we have also observed a lower content of total phospholipids in liver of vitamin A-deficient rats. This was associated with a lower synthesis of the major phospholipid since $\left[{ }^{14} \mathrm{C}\right]$ choline incorporation into phosphatidylcholine

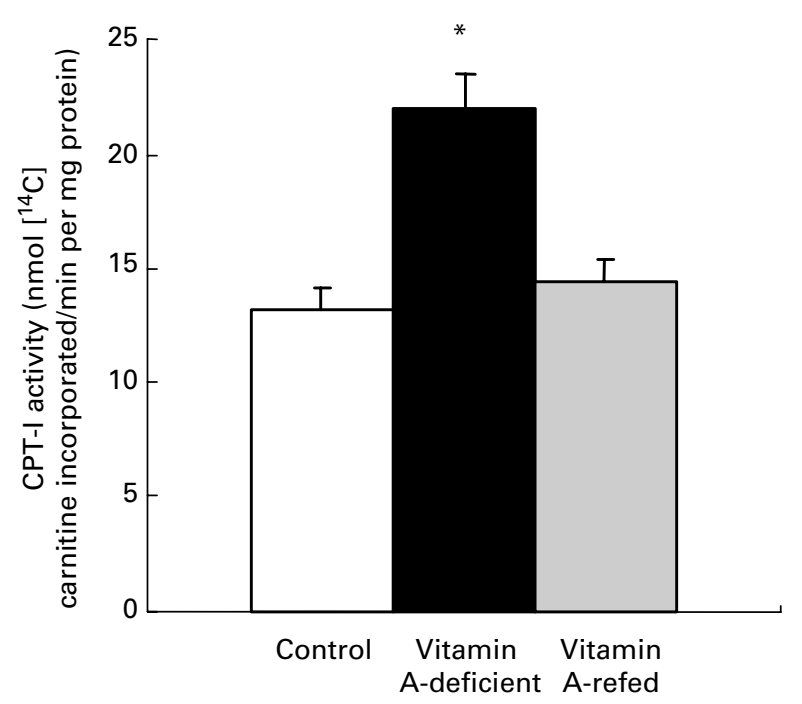

Fig. 2. Carnitine palmitoyltransferase-I (CPT-I) activity in the liver mitochondria of control, vitamin A-deficient and vitamin A-refed rats. For details of procedures, see pp. 264-265. Values are means with their standard errors depicted by vertical bars (eight rats per dietary group). Mean value was significantly different from those of the control group and the vitamin A-refed group: ${ }^{*} P<0.001$. 
Table 5. Effect of vitamin A deficiency on liver mitochondrial lipid compositions ( $\mathrm{mg} / \mathrm{g}$ protein; eight rats per dietary group) $\ddagger$

(Mean values with their standard errors)

\begin{tabular}{|c|c|c|c|c|c|c|}
\hline & \multicolumn{2}{|c|}{ Control } & \multicolumn{2}{|c|}{ Vitamin A-deficient } & \multicolumn{2}{|c|}{ Vitamin A-refed } \\
\hline & Mean & SEM & Mean & SEMQ & Mean & SEM \\
\hline Cholesterol & 5.42 & 0.46 & $4 \cdot 80$ & 0.59 & $5 \cdot 60$ & 0.57 \\
\hline Triacylglycerols & $6 \cdot 10$ & 0.32 & $8 \cdot 76^{\star \star}$ & 0.45 & 7.51 & 0.38 \\
\hline Phospholipids & $90 \cdot 02$ & 6.83 & $63.50^{\star *} \dagger$ & 4.79 & $80 \cdot 12$ & $3 \cdot 16$ \\
\hline Cholesterol/phospholipids & 0.060 & 0.006 & $0.075^{\star}$ & 0.008 & 0.071 & 0.009 \\
\hline
\end{tabular}

Mean values were significantly different from those of the control group (one-way ANOVA): ${ }^{*} P<0.05 ;{ }^{* \star} P<0.01$. Mean values were significantly different from those of the vitamin A-refed group (one-way ANOVA): $† P<0.05$. ‡For details of procedures, see pp. 264-265.

Table 6. Effect of the diet on phospholipid compositions of liver mitochondria (percentage of total lipid phosphorus $(\mathrm{w} / \mathrm{w})$; eight rats per dietary group) $\ddagger$

(Mean values with their standard errors)

\begin{tabular}{|c|c|c|c|c|c|c|}
\hline & \multicolumn{2}{|c|}{ Control } & \multicolumn{2}{|c|}{ Vitamin A-deficient } & \multicolumn{2}{|c|}{ Vitamin A-refed } \\
\hline & Mean & SEM & Mean & SEM & Mean & SEM \\
\hline Cardiolipin & 22.05 & 1.63 & $15 \cdot 06^{\star \star}$ & 1.05 & $18 \cdot 61$ & 1.75 \\
\hline Phosphatidylcholine & $44 \cdot 10$ & $2 \cdot 01$ & $49 \cdot 14$ & $1 \cdot 70$ & $45 \cdot 67$ & $2 \cdot 30$ \\
\hline Phosphatidylethanolamine & $27 \cdot 04$ & 1.64 & $28 \cdot 10$ & 1.88 & 26.51 & 2.02 \\
\hline Sphingomyelin & 1.74 & 0.07 & 1.67 & 0.09 & 1.81 & 0.11 \\
\hline Phosphatidylserine + phosphatidylinositol & $5 \cdot 08$ & 0.84 & $6 \cdot 01$ & 0.96 & $6 \cdot 89$ & 0.79 \\
\hline
\end{tabular}

Mean values were significantly different from those of the control group (one-way ANOVA): ${ }^{* *} P<0 \cdot 01$.

‡For details of procedures, see pp. 264-265.

decreased. In addition, the decreased incorporation of $\left[{ }^{14} \mathrm{C}\right]$ acetate into saponifiable lipids and the low activity of ACC indicated a decrease in fatty acid synthesis, suggesting a low availability of fatty acids to form phospholipids in the liver of vitamin Adeficient rats. These metabolic changes can possibly affect the serum lipid levels. In particular, phospholipids are an important component of HDL, the level of which is reduced in serum of vitamin A-deficient rats.

Vitamin A deficiency did not alter liver cholesterol synthesis, since incorporation of $\left[{ }^{14} \mathrm{C}\right]$ acetate into cholesterol was not modified compared with control. However, there was a decrease of the serum cholesterol associated with a low HDL-cholesterol level. Although the mechanism of this hypolipidaemic effect is not the purpose of the present study, the possibility that vitamin A deficiency may play a role in altering lipoprotein secretion from the liver into the circulation can be considered. It has been shown that retinoic acid increases in a dose-dependent manner the secretion of apo A I, B 100, C III and A II in cultures of Hep G2 cells (Liu et al. 2001). In addition, we have observed a decrease in serum triacylglycerol levels in vitamin A-deficient rats.

Fatty acid utilization through the mitochondrial $\beta$-oxidation pathway was clearly affected by the vitamin A deficiency. The increase in serum $\beta$-hydroxybutyrate was attributed to high CPT-I activity in liver mitochondria of vitamin A-deficient rats. This fact was associated with the low ACC activity, which catalyses the formation of malonyl-CoA (LópezCasillas \& Kim, 1991), a strong inhibitor of synthesis and activation of CPT-I (Jackson et al. 2000). Malonyl-CoA sensitivity is an intrinsic property of L-CPT-I since carnitine
palmitoyltransferase-II does not possess a malonyl-CoA binding domain (Cohen et al. 1998).

Furthermore, the high CPT-I activity coincided with an enhanced CPT-I mRNA level, and the low ACC activity was in agreement with a decreased ACC gene. The incorporation of vitamin $\mathrm{A}$ into the diet of vitamin A-deficient rats considerably improved both activities and genes expressions of CPT-I and ACC.

To gain more insight into the control of fatty acid metabolism by vitamin A deficiency, we have examined the transcriptional regulation of the PPAR $\alpha$ gene, which plays a pivotal role in the transcriptional regulation of genes involved in cellular lipid metabolism (Issemann et al. 1993; Kersten, 2002). The low PPAR $\alpha$ mRNA expression in vitamin A-deficient rats could be explained by low fatty acid synthesis and the depletion of retinoids, since fatty acids are able to activate PPAR $\alpha$ (Forman et al. 1997), and 9-cis retinoic acid is the ligand for the retinoid $\mathrm{X}$ receptor, which in turn acts as the dimerization partner for $\operatorname{PPAR} \alpha$. The expression of the $\operatorname{PPAR} \alpha$ gene was restored with a vitamin A-sufficient diet, indicating that it is involved in the effects of vitamin $\mathrm{A}$ deficiency on liver fatty acid metabolism.

We also observed a significant decrease of total phospholipid content in mitochondria of vitamin A-deficient rats given an increased cholesterol-phospholipid relation, suggesting that membrane fluidity can be altered. Kon'IIa et al. (1990) found that vitamin A deficiency in maturing male rats changes the lipid composition of liver microsomal membranes increasing the cholesterol/phospholipid ratio. We have seen a significant decrease (by $36 \%$ ) of mitochondrial cardiolipin 

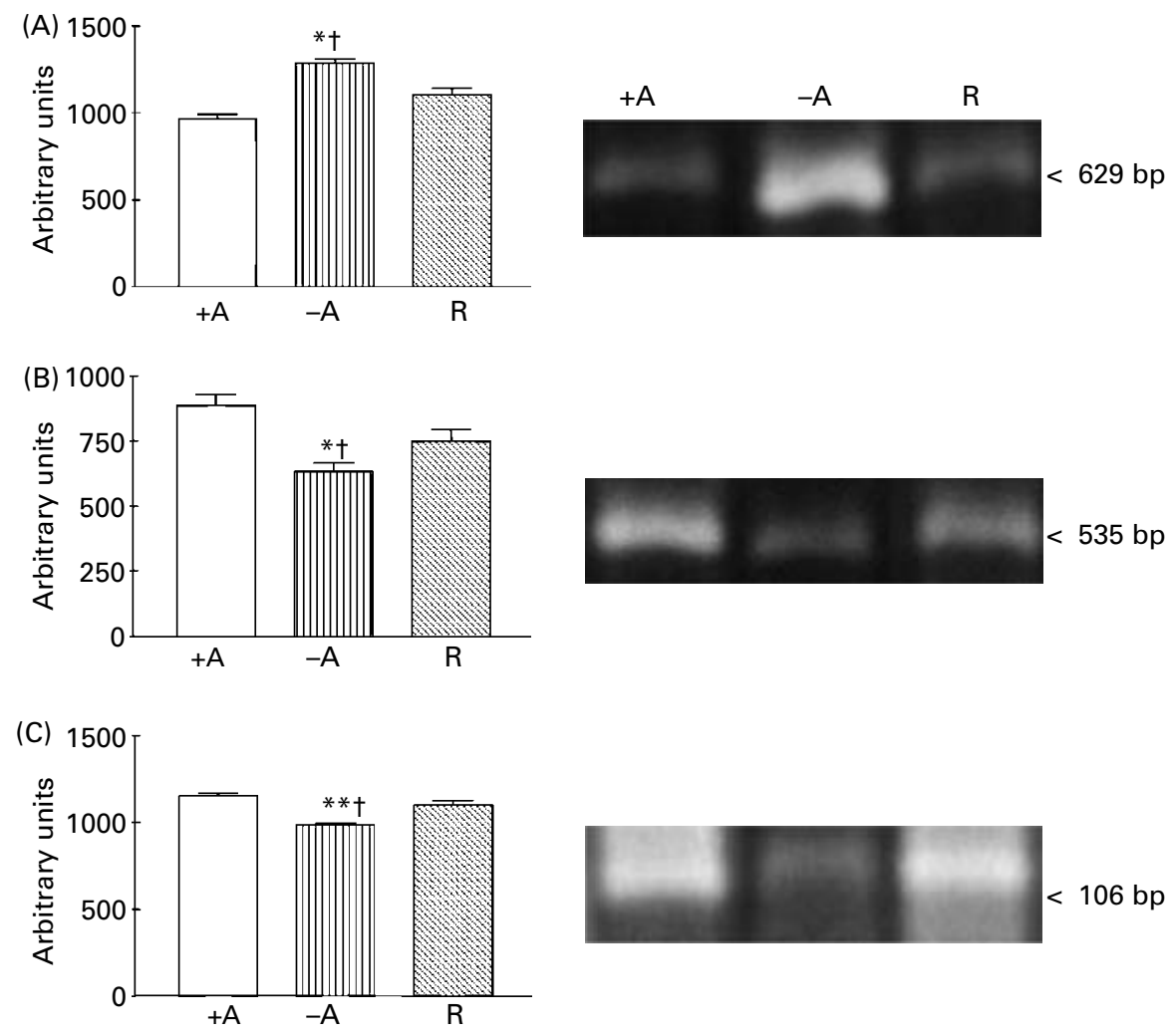

(d)

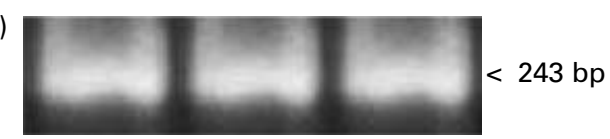

Fig. 3. Expression of genes involved in liver fatty acid metabolism. For details of procedures, see pp. 264-265. Bars show quantification of the intensity of the fragment bands in relation to the intensity of the internal control bands. Values are means with their standard errors depicted by vertical bars (four rats per dietary group). + A, control; $-\mathrm{A}$, vitamin A-deficient; $\mathrm{R}$, vitamin A-refed rats. Mean value was significantly different from that of the $+\mathrm{A}$ group: ${ }^{\star} P<0.001 ;{ }^{\star *} P<0.01$. Mean value was significantly different from that of the $\mathrm{R}$ group: $\dagger P<0.01$. The photographs are ethidium bromide-stained agarose gels of carnitine palmitoyltransferase-I PCR products (A); acetyl-CoA carboxylase PCR products (B); PPAR $\alpha$ PCR products (C); $\beta$-actin PCR products, used as an internal control (D). The results are typical of four independent observations.

content induced by vitamin A deficiency that could also indicate a mitochondrial dysfunction. Cardiolipin is recognized to be an essential phospholipid in eukaryotic energy metabolism and in maintaining mitochondrial structure and function. A direct relationship between cardiolipin loss and cytochrome $c$ release from mitochondria has been identified as an initial step in the phatway to apoptosis (McMillin \& Dowhan, 2002). In addition, in a previous report we showed that vitamin A deprivation for 3 months induces oxidative stress in rat liver (Anzulovich et al. 2000). It is known that reactive oxygen species affect the activity of heart mitochondrial complex III leading to mitochondrial dysfunction via cardiolipin oxidative damage. This has been mainly ascribed to a specific loss in mitochondrial content of cardiolipin (Petrosillo et al. 2003). The increased triacylglycerol content could be due to a decrease in the lipid membrane turnover, as has been suggested by Barber et al. (2000), who found changes in lipid composition of liver mitochondria associated with oxidative damage induced by chronic vitamin A deficiency.

Considering all these observations, it is also conceivable that modified mitochondria lipid composition can alter the input of fatty acids and consequently their $\beta$-oxidation in the liver of vitamin A-deficient rats.

The present results confirm and extend the observation that vitamin A depletion rendered important alterations in total liver lipid metabolism and mitochondrial lipid compositions. In particular, the results show that 3 months of feeding the vitamin A-deficient diet to the rats causes a significant increase in mitochondrial fatty acid oxidation by an enhancement of CPTI activity and gene expression. This is mainly attributed to a decrease in availability of malonyl-CoA due to a diminution of ACC activity and gene expression. The present observation establishes an explanation for vitamin A action, which could control energetic mitochondrial processes in situations such as retinoic treatment.

\section{Acknowledgements}

María Sofía Gimenez is a member of the National Investigations Council of Science and Technology (CONICET), Argentina. 


\section{References}

Abell LL, Levy BB, Brodie BB \& Kendall FE (1952) A simplified method for the estimation of total cholesterol in serum and demonstration of its specificity. J Biol Chem 195, 357-366.

Alarcon Corredor OM, Silva Larralte T, Chacon Patino A, Pachano Primera YJ, Alarcon AO \& Reinosa J (1996) Changes in liver and kidney phosphorus in guinea pigs exposed to high doses of citamin a (retinol). Acta Cient Venez 47, 127-131.

Allred JB \& Roehrig KL (1978) Heat activation of rat liver acetylCoA carboxylase in vitro. J Biol Chem 253, 4826-4829.

Anzulovich AC, Oliveros LB, Muñoz E, Martínez LD \& Gimenez MS (2000) Nutritional vitamin A deficiency alters antioxidant defenses and modifies the liver histoarchitecture in rat. $J$ Trace Elem Exp Med 13, 343-357.

Barber T, Borrás E, Torres L, García C, Cabezuelo F, Lloret A, Pallardó F \& Viña JR (2000) Vitamin A deficiency causes oxidative damage to liver mitochondria in rats. Free Radic Biol Med 29, 1-7.

Berger J \& Moller DE (2002) The mechanisms of action of PPARs. Annu Rev Med 53, 409-435.

Bieri J, Tolliver T \& Catagnani G (1979) Simultaneous determination of alpha-tocopherol and retinol in plasma or red cells by high pressure liquid chromatography. Am J Clin Nutr 32, $2143-2149$.

Blomhoff R, Green MH, Berg T \& Norum KR (1990) Transport and storage of vitamin A. Science 250, 399-404.

Chambon P (2005) The nuclear receptor superfamily: a personal retrospect on the first two decades. Mol Endocrinol 19, 1418-1438.

Chance B, Sies H \& Boveris A (1979) Hydroperoxide metabolism in mammalian tissue. Physiol Rev 59, 527-605.

Choi JW \& Choi HS (2000) The regulatory effects of thyroid hormone on the activity of 3-hydroxy-3-methylglutaryl coenzyme A reductase. Endocr Res 26, 1-21.

Cohen I, Kohl C, McGarry JD, Girard J \& Prip-Buus C (1998) The $\mathrm{N}$-terminal domain of rat liver carnitine palmitoyltransferase 1 mediates import into the outer mitochondrial membrane and is essential for activity and malonyl-CoA sensitivity. $J$ Biol Chem 273, 29896-29904.

Dicken CH (1981) Elevation of blood triglyceride levels secondary to administration of vitamin A. Arch Dermatol 117, 189-190.

Esser V, Brown NF, Cowan AT, Foster DW \& McGarry JD (1996) Expression of a cDNA isolated from rat brown adipose tissue and heart identifies the product as the muscle isoform of carnitine palmitoyltransferase I (M-CPT I). M-CPT I is the predominant CPT I isoform expressed in both white (epididymal) and brown adipocytes. J Biol Chem 271, 6972-6977.

Fawzi WW, Chalmors TC, Herrera MG \& Mosteller F (1993) Vitamin A supplementation and child mortality - a meta analysis. J Am Med Assoc 269, 898-903.

Folch J, Lees M \& Sloane-Stanley GH (1957) A simple method for the isolation and purification of total lipids from animal tissues. J Biol Chem 2, 497-509.

Forman BM, Chen J \& Evans RM (1997) Hypolipidemic drugs, polyunsaturated fatty acids, and eicosanoid are ligands for peroxisome proliferator-activated receptors $\alpha$ and $\delta$. Proc Natl Acad Sci U S A 94, 4312-4317.

Grantham BD \& Zammit VA (1986) Restoration of the properties of carnitine palmitoyltransferase I in liver mitochondria during refeeding of starved rats. Biochem J 239, 485-488.

Hoekstra M, Kruijt JK, Van Eck M \& Van Berkel TJ (2003) Specific gene expression of ATP-binding cassette transporters and nuclear hormone receptors in rat liver parenchymal, endothelial, and Kupffer cells. J Biol Chem 278, 25448-25453.

Humphrey JH, West KP Jr \& Sommer A (1992) Vitamin A deficiency and attributable mortality among under-5-year-olds. Bull WHO 70, $225-232$
Issemann I, Prince RA, Tugwood JD \& Green S (1993) The peroxisome proliferator-activated receptor:retinoid $\mathrm{X}$ receptor heterodimer is activated by fatty acids and fibrate hypolipidaemic drugs. J Mol Endocrinol 11, 37-47.

Jackson VN, Zammit VA \& Price NT (2000) Identification of positive and negative determinants of malonyl-CoA sensitivity and carnitine affinity within the amino termini of rat liver- and muscle-type carnitine palmitoyltransferase I. J Biol Chem 275, 38410-38416.

Kersten S (2002) Peroxisome proliferator activated receptors and obesity. Eur J Pharmacol 440, 223-234.

Khanna A \& Reddy TS (1983) Effect of undernutrition and vitamin A deficiency on the phospholipid composition of rat tissues at 21 days of age. I. Liver, spleen and kidney. Int J Vitam Nutr Res 53, 3-8.

Kon' IIa, Sokolov AI, Filatov IIu, Deev AI \& Gapparov MM (1990) Vitamin A and microsomal membranes: the effect of retinol deficiency on lipid microviscosity and phospholipid turnover in rat liver microsomes. Biokhimiia 55, 982-987.

Korichneva I, Waka J \& Hammerling U (2003) Regulation of the cardiac mitochondrial membrane potential by retinoids. J Pharmacol Exp Ther 305, 426-433.

Liu H, Wu Z \& Liu B (2001) Effects of retinoic acid on secretion of apolipoproteins A I, A II, B 100, C III and E by cultures of HepG2 cells. Ниа Xi Yi Ke Da Хие Хие Ваo 32, 52-54.

López-Casillas F \& Kim K-H (1991) The $5^{\prime}$ untranslated regions of acetyl coenzyme A carboxylase mRNA provide specific translational control in vitro. Eur J Biochem 201, 119-127.

Lowry OH, Rosebrough NJ, Farr AL \& Randall RJ (1951) Protein measurement with the Folin phenol reagent. J Biol Chem 193, $265-275$.

McGarry JD (1995) The mitochondrial carnitine palmitoyltransferase system: its broadening role in fuel homoeostasis and new insights into its molecular features. Biochem Soc Trans 23, 321-324.

McGarry JD \& Brown NF (1997) The mitochondrial carnitine palmitoyltransferase system. Eur J Biochem 244, 1-14.

McGarry JD, Mills SE, Long CS \& Foster DW (1983) Observations on the affinity for carnitine, and malonyl-CoA sensitivity, of carnitine palmitoyltransferase I in animal and human tissues. Biochem $J$ 214, 21-28.

McMillin JB \& Dowhan W (2002) Cardiolipin and apoptosis. Biochim Biophys Acta 1585, 97-107.

Oliveros LB, Vega VA, Anzulovich AC, Ramírez DC \& Giménez MS (2000) Vitamin A deficiency modifies antioxidant defenses and essential element contents in rat heart. Nutr Res 20, 1139-1150.

Olson JA (1982) New approaches to methods for the assessment of nutritional status of the individual. Am $J$ Clin Nutr 35, $1166-1168$.

Ouamrane L, Larrieu G, Gauthier B \& Pineau T (2003) RXR activators molecular signalling: involvement of a PPAR alphadependent pathway in the liver and kidney, evidence for an alternative pathway in the heart. $\mathrm{Br} J$ Pharmacol 138, $845-854$.

Petrosillo G, Ruggiero FM, DiVenosa N \& Paradies G (2003) Decreased complex III activity in mitochondria isolated from rat heart subjected to ischemia and reperfusion: role of reactive oxygen species and cardiolipin. FASEB $J$ 17, 714-716.

Rauser G, Fluster S \& Yamamoto A (1970) Two dimensional thinlayer chromatographic separation of polar lipid and determination of phospholipid analysis of spots. Lipids 5, 494-496.

Reeves PG, Nielsen FH \& Fahey GC Jr (1993) AIN-93 purified diets for laboratory rodents: final report of the American Institute of Nutrition Ad Hoc Writing Committee on the Reformulation of the AIN-76A. Rodent Diet J Nutr 123, 1939-1951.

Ruff SJ \& Ong DE (2000) Cellular retinoic acid binding protein is associated with mitochondria. FEBS Lett 24457, 1-5. 
Sardesai VM \& Manning JA (1968) Determination of triglycerides in plasma and tissues. Clin chem 14, 156-161.

Wright GL, Wang S, Fultz ME, Arif I, Matthews K \& Chertow BS (2002) Effect of vitamin A deficiency on cardiovascular function in the rat. Can J Physiol Pharmacol 80, 1-7.
Zak B, Moss N, Boyle AS \& Zlatkis A (1954) Reactions of certain unsaturated steroids with acid iron reagent. Anal Chem 26, 776-777.

Zhou YT, Wang ZW, Higa M, Newgard CB \& Unger RH (1999) Reversing adipocyte differentiation: implication for treatment of obesity. Proc Natl Acad Sci U S A 96, 2391-2395. 